\title{
The Significance of Time, Place and Traumatic Experience on at-Risk Youths' View of their Well-Being: A Preliminary Study
}

\author{
Silvia Exenberger ${ }^{1}$ (D) Stefanie Reiber $^{2}$
}

Accepted: 7 April 2020 / Published online: 23 April 2020

(C) The Author(s) 2020

\begin{abstract}
This preliminary study explores the perspectives of at-risk youths from different cultural backgrounds on their well-being. We propose that youths" "well-being awareness" - i.e. what sources of well-being adolescents spontaneously become aware of when they are asked about - is strongly related to their socio-cultural context, their life experiences, and the time when they reflect about it. This study focused on the meaning of well-being sources, which were constructed by youths from different cultural backgrounds who faced different traumatic life experiences. We developed and applied a theoretical framework to understand youths' well-being awareness. Focus group discussions were analyzed of 48 male youths aged 12-18 years. They either faced the Indian Ocean Tsunami in 2004 (11 boys from South India), or severe intra-familial conflicts (17 European boys), or were unaccompanied minor refugees (20 boys of Asian and African origin). Youths were asked what makes them happy and sad and about their coping strategies, only followed by questions for clarification. First, the data were analyzed inductively based on grounded theory. Second, the gained well-being descriptions were deductively allocated to the most basic elements of human well-being according to White (2008): material, subjective and relational dimension. Through this allocation process the influence of the socio-cultural context (place), life-experience, and time on the meaning of well-being of each youth group became clear. Well-being should be viewed as a process: on the one hand youths conceptions of well-being are deeply rooted in their culture of origin, on the other hand the importance of well-being and its indicators change depending on youths' traumatic experience and the time of asking about it.
\end{abstract}

Keywords Youths' view on well-being - Well-being awareness - Theoretical framework of well-being awareness $\cdot$ Culture $\cdot$ Traumatic experience

Silvia Exenberger

silvia.exenberger-vanham@ tirol-kliniken.at

Extended author information available on the last page of the article 


\section{Introduction}

What is good for children and adolescents? What makes a good life for them? Experts, parents or institutions tell children and adolescents what is good or best for them. Their definitions correspond to the term child well-being indicators (Ben-Arieh et al. 2014; McCarthy and Marks 2010), which O'Hare (2012) defines as "statistics that provide a sense of whether a group of children enjoy a good quality of life" (p. 79). Indicators are grouped together to so-called life domains (e.g., relationships, education), which are the broadest categories in respect of child well-being subareas (Moore 2019). Measures of overall child well-being indicators have been developed using composite indices from a collection of indicators that cover a variety of domains, instead of measuring only one dimension (Lamb and Land 2014; O'Hare and Gutierrez 2012). In short, child wellbeing is a multi-faceted concept that covers a plethora of well-being themes (Ben-Arieh et al. 2014), and in quantitative research well-being is defined implicitly through child well-being indicators. These measures are social constructs that reflect the norms and values of the scientific community and the contexts in which these constructs are developed and applied (Fattore et al. 2019). In this sense well-being is a normative construct with limited generalizability across time and space (ibid.). This is underscoring Christopher and Hickinbottom's (2008) notion of happiness and wellbeing that these concepts cannot transcend temporal and cultural boundaries.

In line with Christopher and Hickbottom's critique that positive psychology in general, and the research field of well-being specifically, is pervaded by Western cultural values and assumptions, White $(2008,2010)$ identified culture as a key influence on how adults construct their well-being. White's research draws on the work of the Economic and Social Research Council (ESRC) group into Well-Being in Developing Countries $(\mathrm{WeD})$ and suggested that well-being should be understood as a process which should be grounded in a specific time and place. With regard to the concept of time White $(2008,2010)$ pointed out that understandings what well-being is, change with historical time and through people's life-cycle. The concept of place refers to the idea that well-being differs from place to place as individual perceptions about it are grounded in shared meanings through culture - what does it mean for "these" people in "this" place to be doing well? Moreover, White $(2008,2010)$ looked into factors that are important to well-being and identified with her study ".. perhaps the most basic elements of human well-being ...” (Bradshaw et al. 2011, p. 552). According to Camfield et al. (2008) these three interdependent well-being dimensions provide a useful framework for encompassing the diversity of well-being concepts, distinguishing between material (having a good life), relational (living a good live), and subjective (people's perceptions of their lives).

To overcome the strong influence of dominant Western ideologies on the (child) well-being research field (Joshanloo 2014), scholars need to consult adults and children personally to learn about their ideas about what constitutes well-being (Delle Fave et al. 2011). For example the comparative qualitative study "Children's understandings of well-being - global and local contexts" ("Children's Understanding of Well-Being" n.d.) attempts to manage this challenge. This multi-national study starts from the premise that children's understanding of well-being is not context-free or static but embedded in specific histories and contexts with an understanding of time and space as social constructs (Fattore et al. 2019). 
Underpinning the current discourse of child well-being (outlined above) we attempt in the present preliminary study to apprehend young people's subjective ideas of wellbeing. More precisely, we try to capture what we call their "well-being awareness", i.e. what sources of well-being youngsters spontaneously become aware of when they are asked about. We assume that the "well-being awareness" is strongly related to their life experiences, their socio-cultural context, and the time when they reflect about it.

\section{A Theoretical Framework for Understanding Youths" "Well-Being Awareness"}

We draw on both Bronfenbrenner's bio-ecological model of human development (Bronfenbrenner and Morris 1998) and on Schwartz et al.'s theory of basic individual values (2012) as a theoretical framework for understanding youth's well-being from their own perspectives. These two theories are viewed against the background of Gelfand et al.'s (2011) cultural concept of tightness and looseness. White's (2008, 2010) basic elements of human well-being are used to allocate the various well-being factors mentioned by youths on a more abstract level.

\subsection{Bio-Ecological Theory of Human Development}

Bronfenbrenner meant by the ecology of human development that studies should examine the interrelations between the developing person and the changing environment. He conceived the environment as a set of nested structures arranged such as a set of Russian dolls. Bronfenbrenner adapted for his theory Brim's (1975) terminology of microstructure and macrostructure. Brim (1975) used these terms to request childhood social indicators given the changed macrostructures in the U.S. American society (e.g., from a labor-intensive to a machine economy) and its influence on child development. Similarly, Bronfenbrenner wanted to illustrate distal and proximal influences on the developing child by using the terms micro-, meso-, exo-, and macrosystem. The microsystem is the most proximal setting of a child and refers to the activities and interactions that occur in the child's immediate surrounding (e.g., home, child care, playground). Connections between the different structures within the microsystem, e.g., parents - school, constitute the mesosystem. The third environmental layer is the exosystem, which consists of contexts that children are not part of. For example, the parents' work environments are an exosystem influence. Micro-, meso-, and exosystem are embedded in the macrosystem, which embraces the institutional systems of a culture or subculture, such as the economic, social, education, legal and political systems. As Bronfenbrenner's theory had a clear focus on continuity and change, he included a temporal dimension to his model, which he called chronosystem. Within the chronosystem changes that occur over the individual's lifetime caused by events or experiences are taken into account. Such changes can either be normative (the change is expected) such as school entry, or non-normative (unexpected change) such as sudden death of a family member. These experiences or events alter the existing relation between person and environment - creating a developmental change. 


\subsection{Theory of Basic Human Values}

When people think about values they think of what is important to them in life. Schwartz (1992) developed the theory of human basic values, which concerned ten basic values that people in all cultures recognize. According to this theory values are universal because they are grounded in one or more of three universal requirements of human existence (Schwartz 2006): (1) needs of individuals as biological organisms (e.g., self-direction values: organismic needs for control and mastery), (2) requisites of coordinated social interaction (e.g., conformity values: inhibition of inclinations that might disrupt group functioning), and (3) survival and welfare needs of groups (e.g., benevolence values: enhancing the welfare of the in-group). Moreover, the value theory (Schwartz 2006; Schwartz et al. 2012) explicates the structure of dynamic relations among the values, which derives from the fact that actions in pursuit of any value have consequences for other values. For example, pursuing power values (seeking for dominance over people) conflict with pursuing universalism values (societal concern). In 2012, Schwartz et al. refined the values theory and expanded the amount of values into a larger number of more narrowly defined, conceptually distinct values. Schwartz (2006) and Schwartz et al. (2012) arranged the values in a circular structure that portrays the total pattern of relations of conflict and congruity among values. The values focus on personal or social outcomes, and they are grouped into four higher order values: conservation and self-transcendence (social outcome) and openness to change and self-enhancement (personal outcome) (ibid.).

\subsection{Against the Background of Culture: Bio-Ecological Theory and Values Theory}

Gelfand et al. (2011) distinguishes between cultures that are tight (strong norms and low tolerance of deviant behavior) or loose (weak social norms and high tolerance of deviant behavior). The authors theorize that tightness and looseness of nations originate from distal ecological and historical factors (e.g., population density, natural disaster, resource scarcity), and societal processes (socio-political institutions such as education, religion, media). For example, nations with high population density and resource scarcity need strong norms and punishment of deviant behavior to sustain the social coordination of survival. The strength of societal norms and tolerance of deviant behavior is further reflected in the predominance of strong versus weak situations that are recurrent in everyday local worlds. That means tight nations are characterized by a much higher degree of situational constraints (proximal process), which restricts the range of behavior deemed appropriate (e.g., kiss in a restaurant). Strong situational constraints in turn influence the psychological adaptation on a micro-level (e.g., higher dutifulness in tight nations). In short, cultural tightness and looseness can be conceptualized as homogeneity and heterogeneity respectively in values, norms, and behaviors. Similarly, Keller (2007) assumed in her eco-cultural model of child development that distal ecological contexts such as physical environmental structure, population parameters, and socio-economic structures define the framework for socialization strategies consisting of ideas and practices, which directly influence child development. That means parents will use cultural meaningful raising and socialization strategies, which prepare their children to survive and adapt optimally in a given society (ibid.). 
Regarding to the relation of cultural tightness and looseness to other existing cultural constructs, it was shown that tightness and looseness co-occur with collectivism and individualism respectively (Triandis 1995). Collectivism-individualism is based mainly on the ingroup-outgroup distinction, whereas tightness-looseness is relevant to a broad range of situations, i.e. it reflects the rules and norms that are held by a society in general (Chan et al. 1996). On the self-concept level, individuals either hold an interdependent self-construal or an independent self-construal (Markus and Kitayama 1991, 2003) corresponding to collectivism and individualism respectively (Triandis 1995).

\section{4 "Well-Being Awareness"}

The proposed theoretical framework of "well-being awareness" (see Fig. 1) was conceptualized to create a comprehensive understanding of individuals' subjective ideas about what constitutes their well-being. The factors time and place are significant in many respects. At a distal level (ecological and historical factors) the factors time and place merge into one another. That means, for example, history of conflicts or human diseases impact whether a nation is tight or loose (Gelfand et al. 2011) on a macrosystem level. The influence of the macrosystem is then reflected in all lower levels as for example the importance of specific values is impacted by the macrosystem. The proximal level of time consists of "life stage" and "life experience" (normative and non-normative experiences). "Life stage" considers the expected developmental stage of an individual and with regard to his/her "well-being awareness", whereas a specific "life experience" sharpens one's perception concerning the question "what makes a good life?". For example, values that would have taken for granted before a nonnormative life experience, could become of increased importance after. A nonnormative life experience in its most intense form is a traumatic experience. Stressful events potentially disrupt the assumptive world of people (Cann et al. 2010; JanoffBulman 1992). These fundamental assumptions (Janoff-Bulman 1992) and core beliefs (Cann et al. 2010) concern for example the meaning of life, human nature, and the relationship with other people. Thus, individuals are forced to reconfigure their assumptive world, and ruminative processes can lead to transformations within the person, that may drive individuals to a higher level of functioning than prior to the negative event (Calhoun et al. 2010). That means these persons experience posttraumatic growth (PTG, Tedeschi and Calhoun 1995). Also children and adolescents can experience PTG (e.g., Exenberger et al. 2018). Once the individuals have successfully integrated the occurrence in the thought structures used to organize to understand the world and other humans beings (Dyregrov 2010) they experience well-being (Calhoun et al. 2010). Against this background we assume that the traumatic experience molds an individual's "well-being awareness".

We assume that the proposed theoretical framework is also useful to (partly) capture the influence of an acculturation process (Berry 2005) on "well-being awareness". Figure 1 illustrates proximal and distal influences on youths" "well-being awareness" and highlights the importance of time and place.

The main purpose of this preliminary study was to facilitate input from youths about what for them constitutes well-being. We aimed to work out differences in the meanings, which these youths attribute to well-being by applying the proposed theoretical 


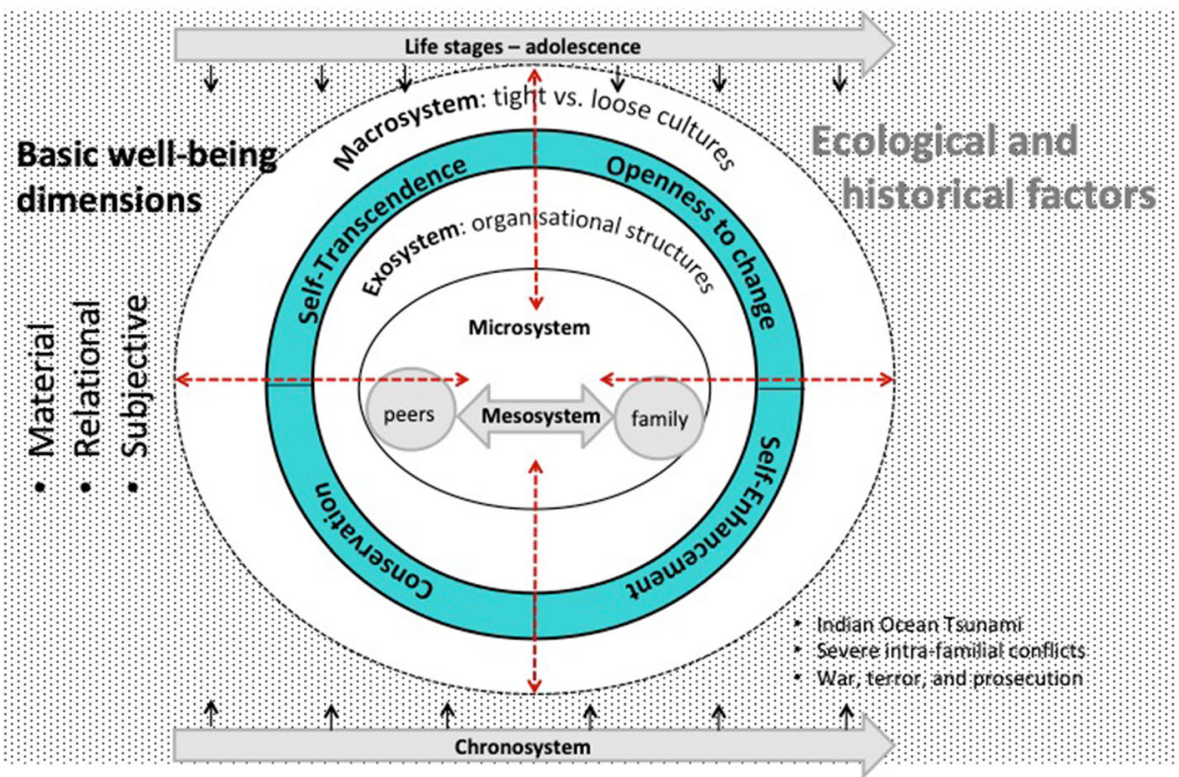

Fig. 1 The effect of time and place: proximal and distal influences on youths' "well-being awareness"

framework. By considering this framework we aimed to extract the influences on youths' "well-being awareness": (1) time - stage of life and personal life experience, and (2) place - cultural background and present place/culture. The youths came from different cultural backgrounds and had experienced different traumatic life events.

\section{Method}

\subsection{Participants}

A total of 48 male adolescents participated in the study. They were grouped according to their life experiences, i.e. youngsters who faced (1) the Indian Ocean Tsunami in 2004, (2) severe intra-familial conflicts, or (3) war, terror, and prosecution. The three groups of youth belonged to different cultural backgrounds: Europe, South India, EastAfrican and South-Asian countries and one country from the Middle East. The European youth from Austria and Germany grew up in an individualistic environment. The South Indian youth grew up in highly collectivistic surroundings (i.e. small, singlecaste fishing hamlets) that were isolated from the Tamil society and the government (Bavinck 2008). According the long-term patterns of cultural tightness and looseness (see above Gelfand et al. 2011) the countries Afghanistan, Eritrea, Pakistan, Somalia, and Syria count among tight cultures. All three groups of youth lived in family-based out-of-home care.

Indian Ocean Tsunami in 2004 Eleven boys from Tamil Nadu, South India directly faced the Tsunami in 2004. The parents of these boys died due to the Tsunami and they had to move to family-based out-of-home care. 
Severe intra-Familial Conflicts Seventeen male adolescents from Austria and Germany also lived in family-based out-of-home care because it was not in their best interest anymore to stay with their parents (e.g., domestic violence, parental substance abuse). The German youngsters came exclusively from Southern Germany, which borders Austria. Due to this geographical and cultural proximity the Austrian and German boys were pooled to create the European sample.

War, Terror, and Prosecution Twenty male adolescents belonged to the group of unaccompanied minor refugees (UMR) who had to leave their country of origin because of war, terror, and prosecution. Unaccompanied minors, who resettle without their parents are a particularly vulnerable group of refugee children. They came from Afghanistan, Eritrea, Pakistan, Somalia, and Syria. The youngsters lived in refugee homes for youths in Austria and Germany.

Even though the three groups of youths faced different traumatic events, it is well known that children and adolescents show common post-traumatic reactions such as strong intrusive thoughts and changes in meaning and values (e.g., Dyregrov 2010). Moreover they all experienced losses, for example, the loss of loved ones, the loss of possessions, personal losses such as control, self-esteem, predictability, security in existence etc. (ibid.). Due to these broad commonalities we decided to compare their explorations of their well-being sources.

The eligibility criteria of the male adolescents included their age (12 to 18 years), the experience of a traumatic event according to the criterion A of post-traumatic stress disorder (PTSD) in DSM-V (American Psychiatric Association 2013), and living in out-of-home care. Originally, in the first two groups also younger children (aged 8 to 11 years) and girls participated in same-sex and same-age group discussions (see Exenberger et al. 2019). In the present study data were analyzed only for the older male age group (12-17 years) because there were no girls and younger children within the UMR group. With regard to "time" data was collected in the long-term aftermath of trauma. More precisely, the Indian adolescents and the UMR took part in the focus group discussions four and two years post-trauma respectively - when they have entered out-of-home care. The European youth who participated in the focus groups have been at least two years in out-of-home care.

\subsection{Focus Group Discussions}

The focus group discussion as described by Vogl (2005) for children was adapted to adolescents to gain an understanding about what constitutes their well-being and illbeing respectively. Due to the fact that peers strongly influence each other (Steinberg and Monahan 2007) we emphasized at the beginning of each focus group that there are no right and wrong answers. Moreover we stressed that everyone is expert of his life and that we are interested in each opinion. Together with the adolescents we developed some basic rules for our discussion (e.g., one person talks at a time; it is okay to disagree). During the focus group discussion we promoted the interaction between the participants - they were encouraged to ask clarifying questions to one another (Bagnoli and Clark 2010). Based on Fattore et al.'s (2007) study findings, which revealed that children associated with the term well-being "positive feeling states such as happiness, 
excitement and peacefulness or calm ..." (Fattore et al. 2007, p. 17) we used the term "happiness" for the formulation of our first question. With the second question we wanted to gain an understanding of what hinders their well-being. Finally, we attempted to explore adolescents' abilities to transform from an unhappy to a happy state of feeling. All participating adolescents were asked the following open (main) questions, which they were encouraged to answer in a non-restrictive way:

- What (in general) gives you happiness? What makes you happy? What makes a good life for you?

- What makes you feel sad or not good?

- If you feel sad or not good, what helps you to feel good again?

All questions were only supported by further questions for clarification and by asking the youngsters for examples from their everyday lives. We consciously did not ask more precise questions about specific well-being themes because we did not want to give the adolescents ideas what might constitute their wellbeing. With other words, we wanted to capture the adolescents" "well-being awareness", i.e. what sources of well-being they spontaneously become aware of when they are asked about.

\subsection{Procedure}

For the work with the Indian sample a male and a female bilingual university student (English and Tamil) from the same culture were trained in the study's objectives. They acted not only as interpreters but also as cultural intermediaries. This includes the act of linking groups or persons of different cultural backgrounds to facilitate collaboration. The focus groups with the European sample and the UMR were conducted in German, which was the native language of the authors who led the focus group discussions. German was the native language of the European sample and the UMR had sufficient command of the German language.

The adolescents' caregivers gave written and oral consent for the adolescents' participation. A youth-friendly version of informed consent was given to the youngsters, who gave their oral consent. At any stage of the research process, the youngsters could refuse to participate. No adolescent wanted to leave the group.

All focus group discussions were initialized with an ice-breaker game. The "happy" and "sad" topic were each introduced with a visual stimulus. After the adolescents had identified both topics of the visual stimuli they discussed each topic in small groups or thought about it individually. They shared their results in the plenum. For the last question the adolescents were asked to use modeling clay or use colors and paper to derive a symbol of their (coping) strategy that they use to come out of a sad or unhappy mood. Their symbols were discussed in the group. In case they did not want to do "artwork", they also could write. At the end of the focus group discussions we provided drinks and snacks in order to make sure that the adolescents left the sessions in a good mood. In case adolescents got upset during the research process, we helped them to feel better again by offering personal conversations with the researcher. Furthermore, they had the opportunity to consult the psychologist or the educationalist of their organization. 
All focus groups were audio-taped. The group discussions took up to two hours due to the involvement of play elements and working with different stimulating materials. Each group consisted of a maximum of six adolescents. Two focus groups were implemented with the Indian sample, four with the European sample and five with the UMR. All focus groups in India were conducted from February to April 2009, those in Austria and Germany from May to July 2011, and those with the UMR in June and July 2017. The ethics committee of the funding agency approved the study.

\subsection{Data Preparation and Analysis}

\subsubsection{Inductive Approach}

The Tamil answers of the recorded focus group discussions were translated into English by the university students. All transcribed interviews (English and German) were analyzed in-depth using the open coding process according to the Grounded Theory by which data are broken down analytically (Corbin and Strauss 2008). During this coding process events/actions/interactions are compared with others for similarities and differences and they are given conceptual labels. In this way similar concepts are grouped together to form subcategories. These subcategories were then grouped and regrouped to identify higher order commonalities called categories using the constant comparative method (ibid.). At the highest level of analysis, categories are bundled into core categories, which are called domains in this study. From the core category it is possible to go back (within the data pool) to the most basic group of data - the concepts and codings, which reflect the adolescents' original statements.

This analyzing process was done for each group individually. The domains, categories and subcategories of each group were contrasted (see Table 1 of the results section).

\subsubsection{A Deductive Approach}

In a next step, we compared all categories and their accompanying subcategories in order to identify similar well-being themes (categories). Then we allocated the similar well-being themes to the three basic interdependent well-being dimensions according to White $(2008,2010)$, namely "material", "relational", and "subjective" (see above). If necessary, we used more abstract terms in order to better reflect the content of a category mentioned by all three youth samples. The new terms mainly originated from the values theory according to Schwartz (2006) and Schwartz et al. (2012). For example, the category "social skills" (inductive approach) was allocated to the wellbeing dimension "relational" (deductive approach), and was renamed to "benevolence values", because the adolescents from the Indian and UMR group named various social skills, which were all counted among this kind of values (see Table 2 of the results section). Furthermore, similar well-being themes named by all three groups - originally identified within the inductive approach - were allocated to different well-being dimensions because the meaning was different. In a last step, we tried to identify the underlying drive of the naming of a well-being source (see Table 3 of the results section). This could be through: 


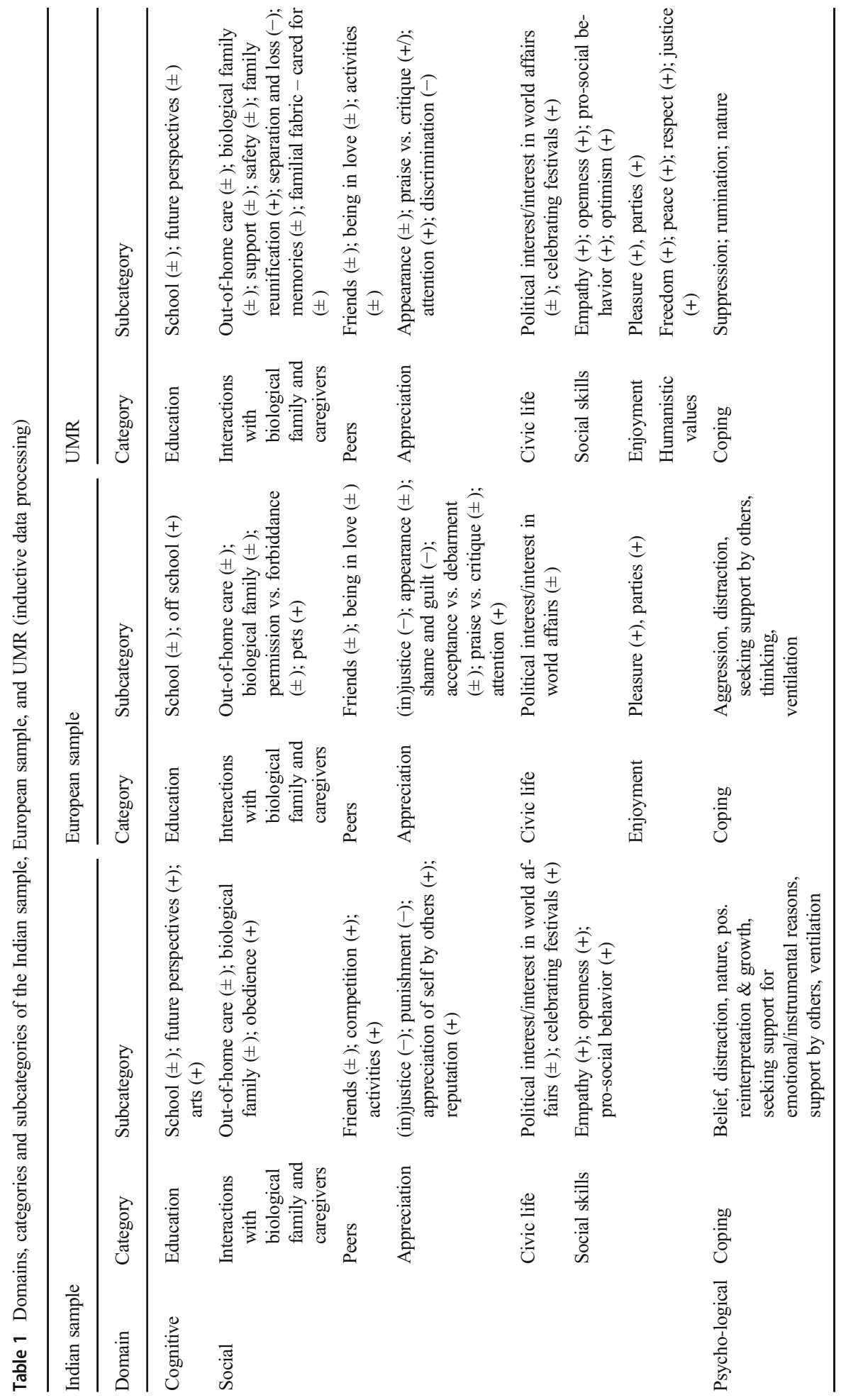




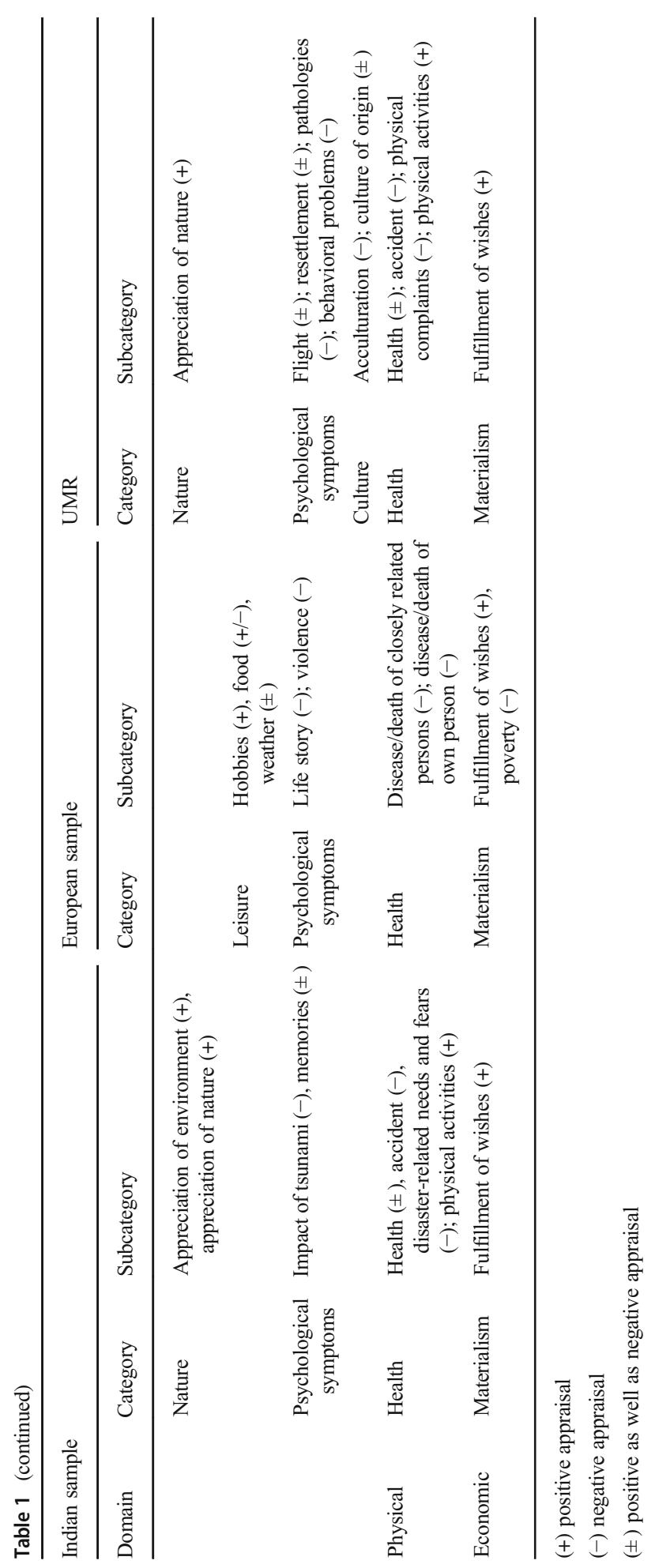


- Culture of origin,

- Acculturation (UMR group only),

- (traumatic) life experience, and/or

- stage of life.

\section{Results}

\subsection{Inductive Approach}

The analysis of the inductive approach of the Indian, European, and UMR focus group discussions resulted in the identification of the same five distinct domains. More in detail, the Indian adolescents revealed eleven categories and thirty-four subcategories,

Table 2 Well-being dimensions according to White $(2008,2010)$ with associated categories derived from the deductive data processing

\begin{tabular}{|c|c|c|c|c|c|}
\hline $\begin{array}{l}\text { WELL-BEING } \\
\text { DIMENSIONS } \\
\text { (White 2008, 2010) }\end{array}$ & $\begin{array}{l}\text { CATEGORIES } \\
\text { Abstract terms } \\
\text { (deductive data } \\
\text { processing) }\end{array}$ & $\begin{array}{l}\text { CATEGORIES } \\
\text { (Inductive data } \\
\text { processing) }\end{array}$ & $\begin{array}{l}\text { Indian } \\
\text { sample }\end{array}$ & $\begin{array}{l}\text { European } \\
\text { sample }\end{array}$ & UMR \\
\hline \multirow[t]{3}{*}{ Material dimension } & $\begin{array}{l}\text { Achievement } \\
\text { values }\end{array}$ & Academic & $\mathrm{x}^{*}$ & $\mathrm{x}$ & $\mathrm{x}$ \\
\hline & Health & Health & $\mathrm{x}$ & $\mathrm{x}$ & $\mathrm{x}$ \\
\hline & Wealth & Materialism & $\mathrm{x}$ & $\mathrm{x}$ & $\mathrm{x}$ \\
\hline \multirow[t]{4}{*}{$\begin{array}{l}\text { Relational } \\
\text { dimension }\end{array}$} & $\begin{array}{l}\text { Relations of love } \\
\text { and care }\end{array}$ & $\begin{array}{l}\text { Originally two categories: } \\
\text { (1) interactions with } \\
\text { biological family and } \\
\text { caregivers, (2) peers }\end{array}$ & $\mathrm{x}$ & $\mathrm{x}$ & $\mathrm{x}$ \\
\hline & Being in love & Being in love & ---** & $\mathrm{x}$ & $\mathrm{x}$ \\
\hline & Appreciation & Appreciation & $\mathrm{x}$ & $\mathrm{x}$ & $\mathrm{x}$ \\
\hline & Civic life & Civic life & $\mathrm{x}$ & $\mathrm{x}$ & $\mathrm{x}$ \\
\hline \multirow[t]{5}{*}{$\begin{array}{l}\text { Subjective } \\
\text { dimension }\end{array}$} & $\begin{array}{l}\text { Benevolence } \\
\text { values }\end{array}$ & Social skills & $\mathrm{x}$ & - & $\mathrm{x}$ \\
\hline & $\begin{array}{l}\text { Universalism } \\
\text { values }\end{array}$ & $\begin{array}{l}\text { Nature (Indian sample \& UMR); } \\
\text { humanistic values (UMR) }\end{array}$ & $\mathrm{x}$ & - & $\mathrm{x}$ \\
\hline & $\begin{array}{l}\text { Tradition and } \\
\text { conformity } \\
\text { values }\end{array}$ & $\begin{array}{l}\text { Expressed in subcategories (Indian } \\
\text { sample); culture (UMR) }\end{array}$ & $\mathrm{x}$ & - & $\mathrm{x}$ \\
\hline & Hedonism values & $\begin{array}{r}\text { Leisure; enjoyment (European } \\
\text { sample); enjoyment (UMR) }\end{array}$ & - & $\mathrm{x}$ & $\mathrm{x}$ \\
\hline & $\begin{array}{l}\text { Stressful } \\
\text { event-related } \\
\text { symptoms }\end{array}$ & Psychological symptoms & $\mathrm{x}$ & $\mathrm{x}$ & $\mathrm{x}$ \\
\hline
\end{tabular}

\footnotetext{
*a specific well-being indicator was named by a specific youth sample

**a specific well-being indicator was not named by a specific youth sample 
the European adolescents named eleven categories and thirty-one subcategories, and within the UMR fourteen categories with forty-four accompanying subcategories could be identified. All domains consisted of positive and negative indicators referring to adolescent's well-being and ill-being respectively. Table 1 shows domains and contrasts categories and subcategories of the Indian, European and UMR sample.

\subsection{Deductive Approach}

Altogether, twelve categories were allocated to the three basic well-being dimensions "material", "relational", and "subjective" (White 2008, 2010). We used these basic well-being dimensions in order to highlight a possible change in the meaning of the mentioned well-being categories. We indicated whether this allocation process would be determined by: (1) cultural influences, (2) acculturation (concerns exclusively UMR), (3) the adolescents' (traumatic) life experiences, and/or (4) stage of life. At this point we wanted to note that the allocation of some inductively identified wellbeing categories (e.g., "social skills") was not always that clear, i.e. they could have been also allocated to another basic well-being dimension. Table 2 shows the three well-being dimensions with its associated categories listed for each adolescent sample. In the following we will provide an explanation concerning the allocation process.

\subsubsection{Material dimension}

According to White $(2008,2010)$ the material dimension refers to the practical welfare (physical health; access to services and amenities) and standards of living (income; wealth and assets; employment and livelihood activities; education and skills; environmental quality). In line with this description we allocated the three categories "achievement values", "health", and "wealth" to this well-being dimension. These categories were mentioned by all three groups of adolescents.

With regard to the category "achievement values" we found on closer examination (i.e. looking into its subcategories and codes) that "achievement values" had a relational meaning for the Indian and the UMR sample. Both groups valued the chance to go to school or doing an apprenticeship so that they can take care of relatives or their future family in a proper way ("I need to have good marks in school. This makes me happy. It is good for me. It is good for my family. I can send money to my family when I get good job", UMR). In addition, the Indian boys stated that they wanted to give back something to those people (e.g., caregiver of family-based out-of-home care) who helped them. Consequently we allocated "achievement values" to the relational well-being dimension. The European youth mentioned that school or apprenticeship makes them happy when they succeed because they viewed success as a positive formal recognition of the self. For this reason "achievement values" became part of the subjective well-being dimension for the European sample. The allocation of the "achievement values" to the relational well-being dimension with regard to the Indian sample and the UMR as well as the allocation of the "achievement values" to the subjective well-being dimension in case of the European sample were possibly driven by culture. In 
addition the relational meaning of "achievement values" stressed by the Indian sample and the UMR seems also to be driven by their traumatic experience.

Even though "health" was for all three groups of adolescents an important source of their well-being and ill-being respectively. Only the European youth emphasized that they sometimes had thoughts about their own death ("When I think I could die ... in two days - it's possible. Or one has to suffer the whole life ... I don't know - this makes me sad") because they were not always sure about the meaning in life. For this reason we allocated "health" for European sample to the subjective well-being dimension. This change in altering the well-being dimension with regard to the European sample was possibly caused by their traumatic experience.

Irrespective of the youths' cultural background and life experience, they all viewed "wealth" in the sense of 'to afford something one needs or wants' as a clear well-being indicator. That means all three groups of adolescents unambiguously linked material resources and well-being. Even though the fulfillment of wishes beyond their basic needs highly contributed to their well-being (one Indian adolescent said: "When we ask for some sweets, we will get some sweets"), the youths' focus was on the satisfaction of their basic needs and on having enough money for an appropriate standard of living. The discussions showed clearly that all youths experienced what it means to live in poverty.

\subsubsection{Relational Dimension}

The centrality of relatedness in life is highlighted through the relational dimension, which is divided into two spheres (1) the social or public, and (2) the intimate or human (White 2008, 2010). The first sphere involves networks of support and obligation; relations with the state (law, politics, welfare); social, political and cultural identities and inequalities; violence, conflict and (in)security. The second sphere comprises relations of love and care, attitudes to life, and scope for personal and collective action and influence (ibid.). Five categories ("relations of love and care" with its special category "being in love"; "appreciation"; "civic life"; "stressful event-related symptoms") were assigned to the relational well-being dimension.

The participating youths - irrespective to which sample they belonged - counted the biological family, caregivers and friends among their most important relationships. These relationships were not only source of their well-being but also of their ill-being. European youth and UMR mentioned also "being in love" as a central form of relationship in their lives. "Being in love" was determined by acculturation with regard to the UMR ("Here [Germany], what makes me happy? Having a girlfriend"), given the fact that UMR often brought up during the group discussions that their culture does not allow them to talk to women and girls and being in face to face contact with them. For the European youths the interest in the opposite gender was culturally determined.

Almost all youths viewed "appreciation" both as a positive and negative well-being indicator. It originated from being in contact with others. In contrast to the Indian and UMR sample, the European youngsters stressed the appreciation of their uniqueness and the importance of asserting their self (e.g., praise). Consequently, we assigned the category "appreciation" to the subjective well-being dimension for the European group (culturespecific).

The majority of the participating adolescents viewed the category "civic life", which covers political interest that concerns the wider society, as important for their well-being. 
The Indian sample and the UMR additionally mentioned their delight to be connected to the community they belong to - for example to be part of a religious celebration. With regard to the UMR the category "civic life" was also allocated to the subjective well-being dimension because as asylum seekers any political decisions concerned their personal future life. Due to their traumatization and their present life situation, political affairs became of high relevance to them.

\subsubsection{Subjective Dimension}

According to White $(2008,2010)$ the subjective dimension consists of (1) the subjective perspective of people on their material and relational dimensions, which corresponds to subjective well-being described by Diener et al. (1997), and (2) cultural values, ideologies and beliefs such as self-concept and personality; hopes, fears and aspirations; sense of meaning(lessness); trust and confidence. To this dimension we counted values, which were shaped by culture, that are "benevolence values", "universalism values", "tradition and conformity values", and "hedonism values". We also put "stressful event-related symptoms" to this dimension.

Both the Indian and UMR sample mentioned "benevolence values" (Schwartz 2006) as well-being indicator concerning relations within the family and other primary groups, thus groups with whom one is in frequent personal contact. Even though "benevolence values" (caring for the welfare of in-group members) contain a strong relational component, we allocated this well-being source to the subjective dimension. This decision was based on White's $(2008,2010)$ definition of this specific well-being dimension, which also comprises the values of a person. For these youngsters group harmony was prioritized and it was reached through the voluntary concern for others. As an UMR said: "If someone did something to me, he lives in my house [refugee home], and I really get upset because he did this to me, I forgive. I forgive because we live together in this house.” This well-being indicator seems to be driven by culture.

"Universalism values" (Schwartz 2006) comprised the welfare of all people and nature. We viewed the high relevance of nature (protection of the environment, world beauty) for the Indian sample and the UMR as a culture-specific and trauma-driven well-being indicator. One Indian adolescent said: "Rain. I like rain very much. Whenever it rains, I take a bath in the rain." The statements of the focus group discussions with the Indian sample and the UMR suggested that the loss of the beauty of nature through the Tsunami or war was not only a culture-driven well-being category, but also a trauma-driven one. The UMR added to the importance of nature, tolerance and societal concern, i.e. probably due to their traumatic experience they emphasized justice, peace, and freedom. As one UMR put it: "Peace. If there is peace, nothing can happen to you. We all need peace. Living in peace is happiness."

"Tradition and conformity values" belonged to the culture-driven well-being indicators and were exclusively mentioned by the Indian and UMR sample. Schwartz et al. (2012) distinguishes two subtypes of "conformity values", namely "interpersonal" (e.g., politeness, respect for parents and elders), and "compliance" (e.g., obedience, self-discipline). The adherence of Indian adolescents to "conformity values" strengthened smooth interactions and group functioning. By comparison, the UMR mainly mentioned "tradition values" that maintained cultural and religious traditions (Schwartz et al. 2012).

Schwartz (2006) assumed that "hedonism values" derive from organismic needs and the pleasure associated with satisfying them. The European youth and UMR were the 


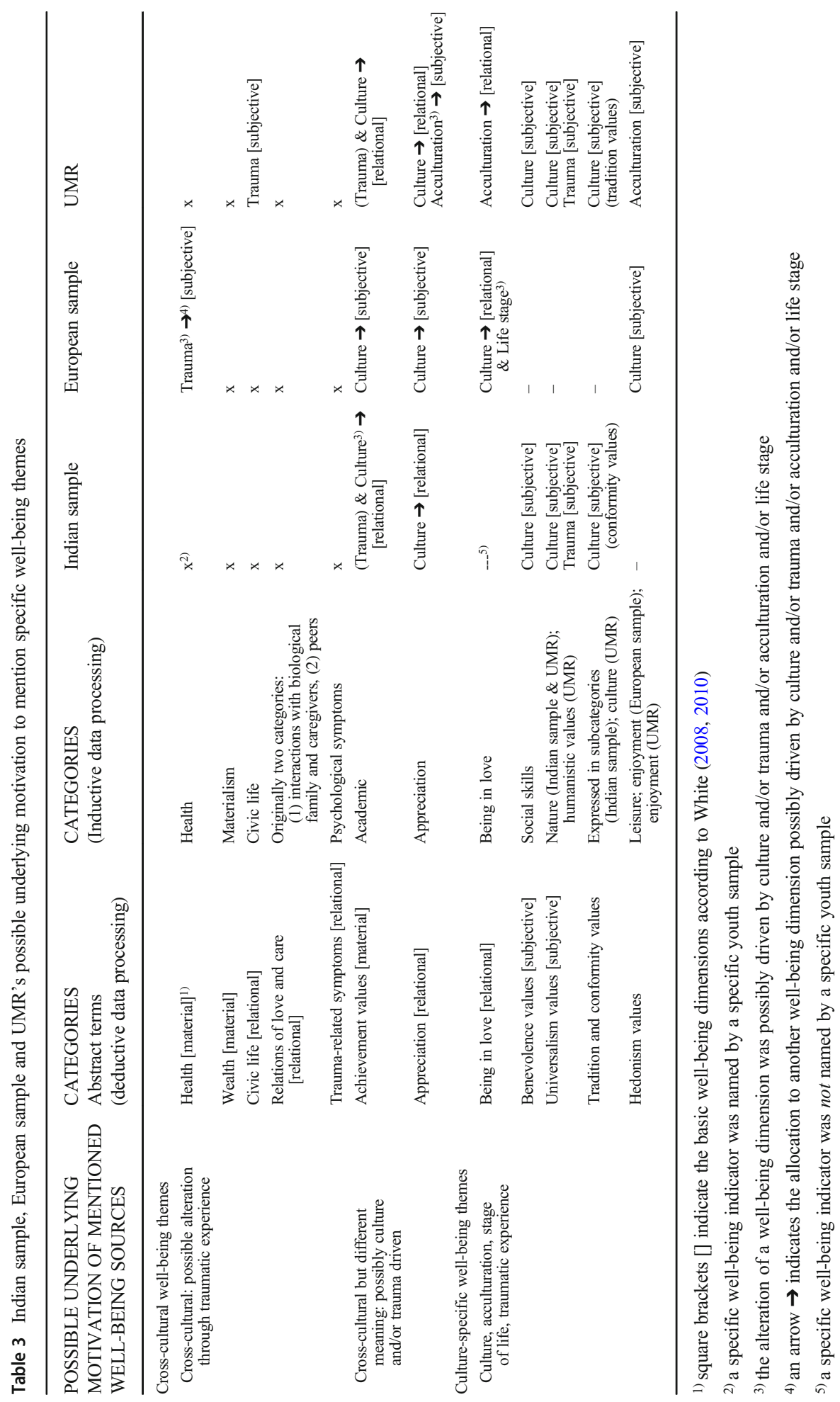


two groups who mentioned hedonism values. Both groups emphasized that "just having fun" or "going to a party" makes them really happy. Having a stress-free time was the main characteristic of such pleasurable activities. With regard to the European sample we assumed that these well-being indicators were culture-driven, whereas hedonism values mentioned by the UMR rather indicated an acculturation process. The Indian sample did not mention any sources of well-being which underscored the pursuit of pleasure.

In connection with the youth's specific traumatic experience (natural disaster, man-made disaster - mass and/or individual) they all mentioned trauma symptoms as source of their illbeing. All youths revealed during their group discussions that they were haunted by bad memories from time to time. Often memories were triggered through situations that reminded them of the past. Even though the three groups of youths faced different traumatic situations, the failure to get basic needs met was a common theme of all of them. For example some of the UMR told: "If there was no place to sleep, we had to sleep on the street. With fear. Terrible fear [...]."

Table 3 shows the results of the focus group discussions with the three youth samples from the perspective of a possible underlying motivation to mention specific well-being sources. We differentiated between cross-cultural well-being themes, which were mentioned by all three groups of youths, and culture-specific well-being themes, which were named by a specific youth sample. The first column of Table 3 provides a possible indication of the youths' underlying motivation mentioning specific wellbeing sources. For example, "health" was originally allocated to the material wellbeing dimension according to White $(2008,2010)$. The statements of the European youths led us to the assumption that "health" is better represented in the subjective well-being dimension with regard to the European sample.

\section{Discussion}

The present study proposed a theoretical framework that is supposed to uncover the underlying motivation of youths when they constitute their own well-being. We captured youths' "well-being awareness" and placed a focus on how time (life stage and traumatic life experience) and place (cultural background and present place of living) might influence their viewpoints on well-being. The results showed that seven out of twelve well-being themes were cross-cultural, i.e. they were mentioned by all groups of adolescents. On closer examination it became clear that some of the themes were cross-cultural with similar meaning and the remaining ones were either molded by a specific traumatic experience or the underlying motivation to mention the well-being sources was driven either by culture and/or acculturation and/or traumatic experience. Five well-being sources were viewed as culture-specific as they were only named by two groups of adolescents (see Table 3). These themes were driven by culture, acculturation, traumatic experience and/or life stage. We will discuss these findings in detail in turn.

It was not surprising that all youths irrespective of their cultural background mentioned the three cross-cultural well-being and ill-being themes respectively: importance of relationships, material security and traumatic symptoms. The fundamental importance of relationships including family, caregivers, friends, and pets (exclusively 
European sample) is a finding that is consistent with previous studies that examined children and young people's perspectives on their well-being in Western and nonWestern cultures (e.g., Crivello et al. 2009; De Berry et al. 2003; Dex and Hollingworth 2012; Vujčić et al. 2019). In addition, all youths associated well-being with a decent standard of living, i.e. they emphasized economic or material resources as they prevented them from social exclusion. In general, Camfield et al. (2010) assume that children or young people only can experience well-being when material security (e.g., having sufficient resources to meet own needs) and relational security (e.g., strong and supportive relationships) are a substantial part of their lives.

"Health" and "civic life" contributed both to the youths' well-being and ill-being. Both well-being themes transformed from a material and relational well-being dimension respectively to a subjective well-being dimension. We assumed that this transformation was caused by a specific traumatic experience faced by one out of the three samples. The European youths - whose traumatic experience was mainly based on child maltreatment - viewed health not only as a well-being source but also as a cause for their ill-being (e.g., thoughts about their own death). Adverse experiences during childhood not only have long-lasting negative physical and mental consequences in adult life (Felitti et al. 1998), they are also related to negative outcomes (e.g., substance abuse, suicide attempts) in adolescence (Jonson-Reid et al. 2012). Even though a large majority of youths showed interest in social and political concerns, politics was most important for UMR because their asylum status depended on the political climate in the respective countries. In other words their future life was heavily influenced by political decisions about UMR. As Wernesjö (2011) noted, the specific political and social context has a major impact on the reception of the UMR and on their life situations in exile.

A large majority of youths mentioned the cross-cultural well-being themes "achievement values" and "appreciation". But it turned out that the meaning of the theme "achievement values" (material well-being dimension) differed between the Indian sample and the UMR compared to the European sample. The meanings were shaped by an adolescent's mode of being that is according to Markus and Kitayama (1991, 2003) either an independent or interdependent self-construal. The former is dominant in Western cultures and is characteristic of an individual who perceives her/himself as being separate from others whereas the latter is dominant in non-Western cultures and is characterized by connectedness with others (ibid.). In this sense the Indian youths and the UMR viewed "achievement values" as a step closer to their wish to take care in a proper way for their biological family and their own future family. Given the destruction of social fabrics from the Tsunami and the war or prosecution this wish was also possibly trauma-driven. In contrast, the European sample referred "achievement values" to the recognition of a personal attainment that leads to self-enhancement and consequently contributes to a youth's well-being. Fattore et al.'s (2009) study with Australian child informants about their own views on well-being found similar results compared to our findings in the European sample. The different meanings across the groups led us to allocate "achievement values" to the subjective well-being dimension (European sample) and to the relational dimension (Indian sample and UMR) respectively. Also within the theme "appreciation" (relational well-being dimension) the divergent aspects of the self were reflected in the youths' statements about their ideas of well-being. The European youths stressed the appreciation of one's uniqueness (e.g., 
appearance), and the importance of asserting the self whereas the Indian youths and the UMR appreciated a critical debate about themselves with (important) others. With respect to the European sample the relational aspect of "appreciation" was changed to a subjective well-being dimension. However with regard to the UMR "appreciation" probably comprised both a relational and a subjective aspect of well-being. We assumed that the relational dimension came to the fore when the UMR appreciated an advice of elders as this is also related to respect and obedience, which is the core of group harmony in collectivist cultures (Greenfield et al. 2003; Tamis-LeMonda et al. 2008). But it seems that the UMR also underwent behavioral shifts as part of their acculturation process. They additionally mentioned the value of the personal gain indicative for the subjective dimension of "appreciation" similar to the European youth. Given the fact that acculturation proceeds at different rates (for example among family members) this can lead to an increase in conflict and stress and to more difficult adaptations (Berry 2005). Even though the UMR underwent the acculturation process without the local presence of family members, they reported about an internal battle between adaptation and loyalty to their culture of origin. This acculturation process (with accompanying internal battle) might also be reflected in culture-specific sources of well-being. For example, the UMR - just as the European youths - mentioned "hedonism values" as a source of their well-being. Regarding to the UMR this theme originates most likely from an acculturation process as hedonism is a dominant view of happiness and well-being in Western cultures (Joshanloo 2014). The acculturating UMR also viewed "tradition values" as a source of their well-being. The subordination to more abstract objects such as religious and cultural customs and ideas (tradition values) versus pleasure or sensuous gratification for oneself (hedonism values) are conflicting values (Schwartz 2006). These opposing values represented the identification with one's cultural identity and the pursuit of contact with members of the newer culture, which is according to Lustig et al. (2004) indicative for integration. However this conflict of values might trigger an inner conflict within the UMR. In contrast to the UMR, the Indian sample named "conformation values" as a culture-specific source of their well-being. According to Schwartz (2006) conformity entails subordination to persons with whom one is in frequent interaction to enhance smooth interaction. These values emphasize self-restraint in everyday interaction (e.g., obedience, politeness, selfdiscipline), which was important to the Indian youths who lived in their culture of origin. With regard to the UMR we also supposed that the well-being source "being in love" originated from their acculturation process. "Being in love" was a relational wellbeing dimension and addressed in a certain way a developmental task (Havighurst 1953). According to Havighurst (1953) developmental tasks are tasks that arise in a social context during an individual lifetime. One specific task during adolescence in a Western cultural context is "achieving new and more mature relations with age-mates of both sexes" (Havighurst 1953, p. 111). "Being in love" could be assumed to be a part of this task. Even though "being in love" as a desirable state of feeling was not tolerated in the UMR's countries of origin, they clearly named this kind of relationship as a source of well-being in the host country as part of their acculturation process. Again similar to "appreciation" and "hedonism values" - this was a well-being source of the UMR that triggered an internal battle with their culture of origin.

The Indian sample and the UMR both mentioned "benevolence values" and "universalism values", which were allocated to the subjective well-being 
dimension according to White $(2008,2010)$ and counted among the culturespecific well-being sources. Both sets of values focus on the welfare of people belonging to the in-group (benevolence values) or the welfare of all people and nature (universalism values) (Schwartz et al. 2012). Dambrun and Ricard (2011) use the term "selflessness" for a style of psychological functioning that is characterized by a low degree of importance given to the self and closely related to characteristics such as altruism, kindness, respect and compassion. In terms of Markus and Kitayama (1991, 2003) "selflessness" corresponds to the interdependent self, which is linked to collectivistic cultures. Given the fact that people tend to adapt their values to their life circumstances (Schwartz 2011) "universalism values" were also assumed to be trauma-driven. The destruction of nature due to natural and human-made disasters could be the reason for the motivation of Indian youths and the UMR to highly value nature and its beauty. In addition the UMR experienced through war and prosecution severe personal restrictions, which could have encouraged them to express societal concern (e.g., social justice, world at peace). Schwartz and Bardi (1997) suggested that the importance of values increase when they are grounded in anxiety and their attainment is blocked.

Several limitations to this study should be mentioned. The sample size was small and comprised only male youths as it was not possible to recruit female UMR. Moreover, all three groups of adolescents underwent a variety of traumatic events. Even though youths - regardless of the kind of traumatic situation they have faced usually share common characteristics in their post-traumatic reactions and trauma processing (Dyregrov 2010), the existence of differences cannot be denied. It would have been preferable to collect data not only of youths with a similar traumatic background, but also at the same time period instead of over a period of eight years. Thus, the generalizability of the results is limited. However, the theoretical framework offers possible directions for considering time and place of individuals as influential factors of the constitution of children and adolescents' well-being. A further limitation concerns the use of focus group discussions with adolescent participants given for example their intense need for peer approval (Norris et al. 2012). Even though we specified rules for the group discussions and emphasized the importance of interaction in case of contradictory opinions, it could be that some youths did not fully add their contributions. Nevertheless we had the impression that the adolescents revealed a lot through this kind of social interaction. In addition, the implementation of the focus groups with the UMR with a female researcher can be viewed as a limitation. Considering cultural differences with regard to the role of women in different sociocultural contexts, it can be assumed that the questioning by a female researcher partly influenced the discussions. With regard to methodology it would have been preferable to involve youths in the entire research process. In this study they have a voice. In future studies youths should be involved in development, planning, and implementation of the study as well as data analysis because participation is assumed to enhance an individual's subjective well-being in the short-term through the act of participating in the research. Moreover, participating in the research can enhance competencies such as self-efficacy (Camfield et al. 2010).

In conclusion, the findings of this preliminary study suggest that the introduced theoretical framework is a useful tool to better understand youths' well-being 
awareness, i.e. how they constitute well-being from their own perspective in a specific place and time. Key issues such as culture of origin, acculturation and the impact of a traumatic experience as motivational factors for the constitution of youths' well-being could be captured.

Acknowledgements The research leading to these results has received funding from the European Community's Seventh Framework Programme FP7-PEOPLE-2007-4-1-IOF, Marie Curie Actions - International Outgoing Fellowships (IOF) under grant agreement no. 220535 (Silvia Exenberger).

Funding Information Open access funding provided by University of Innsbruck and Medical University of Innsbruck.

Open Access This article is licensed under a Creative Commons Attribution 4.0 International License, which permits use, sharing, adaptation, distribution and reproduction in any medium or format, as long as you give appropriate credit to the original author(s) and the source, provide a link to the Creative Commons licence, and indicate if changes were made. The images or other third party material in this article are included in the article's Creative Commons licence, unless indicated otherwise in a credit line to the material. If material is not included in the article's Creative Commons licence and your intended use is not permitted by statutory regulation or exceeds the permitted use, you will need to obtain permission directly from the copyright holder. To view a copy of this licence, visit http://creativecommons.org/licenses/by/4.0/.

\section{References}

American Psychiatric Association. (2013). Diagnostic and statistical manual of mental disorders (5th ed.). Washington, DC: Author.

Bagnoli, A., \& Clark, A. (2010). Focus groups with young people: A participatory approach to research planning. Journal of Youth Studies, 13(1), 101-119. https://doi.org/10.1080/13676260903173504.

Bavinck, M. (2008). Collective strategies and windfall catches: Fisher responses to tsunami relief efforts in South India. Transforming Cultures eJournal, 3(2). https://doi.org/10.5130/tfc.v3i2.923.

Ben-Arieh, A., Casas, F., Frønes, I., \& Korbin, J. E. (2014). Multifaceted concept of child well-being. In A. Ben-Arieh, F. Casas, I. Frønes, \& J. E. Korbin (Eds.), Handbook of child well-being - Theories, methods and policies in global perspective (pp. 1-27). Dordrecht: Springer Science+Business Media. https://doi. org/10.1007/978-90-481-9063-8_134.

Berry, J. W. (2005). Acculturation: Living successfully in two cultures. International Journal of Intercultural Relations, 29(6), 697-712. https://doi.org/10.1016/j.ijintrel.2005.07.013.

Bradshaw, J., Keung, A., Rees, G., \& Goswami, H. (2011). Children's subjective well-being: International Comparative perspectives. Children and Youth Services Review, 33(4). https://doi.org/10.1016/j. childyouth.2010.05.010.

Brim, O. G. (1975). Macro-structure influences on child development and the need for childhood social indicators. American Journal of Orthopsychiatry, 45(4), 516-524.

Bronfenbrenner, U., \& Morris, P. A. (1998). The ecology of development processes. In W. Damon (Series Ed.) \& R. M. Lerner (Vol. Ed.), Handbook of child psychology: Vol. 1. Theoretical models of human development (pp. 993-1027). New York: Wiley.

Calhoun, L. G., Cann, A., \& Tedeschi, R. G. (2010). The posttraumatic growth model: Sociocultural considerations. In T. Weiss \& R. Berger (Eds.), Posttraumatic growth and culturally competent practice: Lessons learned from around the globe (pp. 1-14). Hoboken: Wiley.

Camfield, L., Streuli, N., \& Woodhead, M. (2008). Children's well-being in contexts of poverty: Approaches to research, monitoring and participation. Young Lives. http://oro.open.ac.uk/16990/1/TN12ChildWellBeing.pdf. Accessed 15 September 2019.

Camfield, L., Streuli, N., \& Woodhead, M. (2010). Children's well-being in developing countries: A conceptual and methodological review. European Journal of Development Research, 22(3), 398-416. https://doi.org/10.1057/ejdr.2010.11.

Cann, A., Calhoun, L. G., Tedeschi, R. G., Kilmer, R. P., Gil-Rivas, V., \& Vish- nevsky T., \& Danhauer, S. C. (2010). The Core beliefs inventory: A brief measure of disruption in the assumptive world. Anxiety, Stress, \& Coping, 23(1), 19-34. https://doi.org/10.1080/10615800802573013. 
Chan, D. K.-S., Gelfand, M. J., Triandis, H. C., \& Tzeng, O. (1996). Tightness-looseness revisited: Some preliminary analyses in Japan and the United States. International Journal of Psychology, 31(1), 1-12. https://doi.org/10.1080/002075996401179.

Children's Understanding of Well-Being (n.d.). http://www.cuwb.org Accessed 15 September 2019.

Christopher, J.-C., \& Hickinbottom, S. (2008). Positive psychology, ethnocentrism, and the disguised ideology, of individualism. Theory and Psychology, 18(5), 563-589.

Corbin, J., \& Strauss, A. (2008). Basics of qualitative research (3rd ed.). London: Sage Publications.

Crivello, G., Camfield, L., \& Woodhead, M. (2009). How can children tell us about their wellbeing? Exploring the potential of participatory research approaches within young lives. Social Indicators Research, 90(1), 51-72. https://doi.org/10.1007/s11205-008-9312-x.

Dambrun, M., \& Ricard, M. (2011). Self-centeredness and selflessness: A theory of self-based psychological functioning and its consequences for happiness. Review of General Psychology, 15(2), 138-157. https://doi.org/10.1037/a0023059.

De Berry, J., Nasiry, J., Fazili, A., Hashemi, S., Farhad, S. and Hakimi, M. (2003). The children of Kabul. Discussions with Afghan families. USA: Save the Children Federation.

Delle Fave, A., Brdar, I., Freire, T., Vella-Brodrick, D., \& Wissing, M. P. (2011). The eudaimonic and hedonic components of happiness: Qualitative and quantitative findings. Social Indicators Research, 100(2), 185-207. https://doi.org/10.1007/s11205-010-9632-5.

Dex, S., \& Hollingworth, K. (2012). Children's and young people's voices on their well-being. Childhood Well-Being Research Centre, working paper 16. https://www.gov.uk/government/uploads/system/uploads/attachment data/file/181515/CWRC-00108-2012.pdf. Accessed 15 September 2019.

Diener, E., Suh, E., \& Oishi, S. (1997). Recent findings on subjective well-being. Indian Journal of Clinical Psychology, 24(1), 25-41.

Dyregrov, A. (2010). Supporting traumatized children and teenagers - A guide to providing and understanding and help. London: Jessica Kingsley Publishers.

Exenberger, S., Ramalingam, P., \& Höfer, S. (2018). Exploring posttraumatic growth in Tamil children affected by the Indian Ocean tsunami in 2004. International Journal of Psychology, 53(5), 397-402. https://doi.org/10.1002/ijop.12395.

Exenberger, S., Banzer, R., Christy, J., Höfer, S., \& Juen, B. (2019). Eastern and Western children's voices on their well-being. Child Indicators Research, 12(3), 747-768. https://doi.org/10.1007/s12187-018-9541-8.

Fattore, T., Mason, J., \& Watson, E. (2007). Children's conceptualization(s) of their well-being. Social Indicators Research, 80(1), 5-29. https://doi.org/10.1007/s11205-006-9019-9.

Fattore, F., Mason, J., \& Watson, E. (2009). When children are asked about their well-being: Towards a framework for guiding policy. Child Indicators Research, 2(1), 57-77. https://doi.org/10.1007/s12187008-9025-3.

Fattore, T., Fegter, S., \& Hunner-Kreisel, C. (2019). Children's understandings of well-being in global and local contexts: Theoretical and methodological considerations for a multinational qualitative study. Child Indicators Research. Advance online publication. https://doi.org/10.1007/s12187-018-9594-8

Felitti, V. J., Anda, R. F., Nordenberg, D., Williamson, D. F., Spitz, A. M., Edwards, V., et al. (1998). Relationship of childhood abuse and household dysfunction to many of the leading causes of death in adults: The Adverse Childhood Experiences (ACE) study. American Journal of Preventive Medicine, 14(4), 245-258. https://doi.org/10.1016/S0749-3797(98)00017-8.

Gelfand, M. J., Raver, J. L., Nishii, L., Leslie, L. M., Lun, J., Lim, B. C., Duan, L., Almaliach, A., Ang, S., Arnadottir, J., Aycan, Z., Boehnke, K., Boski, P., Cabecinhas, R., Chan, D., Chhokar, J., D'Amato, A., Ferrer, M., Fischlmayr, I. C., Fischer, R., Fulop, M., Georgas, J., Kashima, E. S., Kashima, Y., Kim, K., Lempereur, A., Marquez, P., Othman, R., Overlaet, B., Panagiotopoulou, P., Peltzer, K., Perez-Florizno, L. R., Ponomarenko, L., Realo, A., Schei, V., Schmitt, M., Smith, P. B., Soomro, N., Szabo, E., Taveesin, N., Toyama, M., van de Vliert, E., Vohra, N., Ward, C., \& Yamaguchi, S. (2011). Differences between tight and loose cultures: A 33-nation study. Science, 332, 1100-1104. https://doi.org/10.1126 /science.1197754.

Greenfield, P. M., Keller, H., Fuligni, A., \& Maynard, A. (2003). Cultural pathways through universal development. Annual Review of Psychology, 54, 461-490. https://doi.org/10.1146/annurev. psych.54.101601.145221.

Havighurst, R. J. (1953). Human development and education. London: Longmans Green and Co LTD..

Janoff-Bulman, R. (1992). Shattered assumptions: Towards a new psychology of trauma. New York: Free Press.

Jonson-Reid, M., Kohl, P. L., \& Drake, B. (2012). Child and adult outcomes of chronic child maltreatment. Pediatrics, 129(5), 839-845. https://doi.org/10.1542/peds.2011-2529. 
Joshanloo, M. (2014). Eastern conceptualizations of happiness: Fundamental differences with Western views. Journal of Happiness Studies, 15(2), 475-493. https://doi.org/10.1007/s10902-013-9431-1.

Keller, H. (2007). Cultures of infancy. Mahwah, London: Lawrence Erlbaum Associates, Publishers.

Lamb, V. L., \& Land, K. C. (2014). Methodologies used in the construction of composite child well-being indices. In A. Ben-Arieh, F. Casas, I. Frønes, \& J. E. Korbin (Eds.), Handbook of child well-being: Theories, methods and policies in global perspective (pp. 2739-2755). https://doi.org/10.1007/978-90481-9063-8_163.

Lustig, S. L., Kia-Keating, M., Knight, W. G., Geltman, P., Ellis, H., Kinzie, J. D., Keane, T., \& Saxe, G. N. (2004). Review of child and adolescent refugee mental health. Journal of the American Academy of Child and Adolescent Psychiatry, 43(1), 24-36. https://doi.org/10.1097/01.chi.0000096619.64367.37.

Markus, H. R., \& Kitayama, S. (1991). Culture and the self: Implications for cognition, emotion and motivation. Psychological Review, 98(2), 224-253.

Markus, H. R., \& Kitayama, S. (2003). Culture, self, and the reality of the social. Psychological Inquiry, 14(3\&4), 277-283.

McCarthy, D., \& Marks, D. F. (2010). Exploring the health and well-being of refugee and asylum seeking children. Journal of Health Psychology, 15(4), 586-595. https://doi.org/10.1177/1359105309353644.

Moore, K. A. (2019). Developing an indicator system to measure child well-being: Lessons learned over time. Child Indicators Research. Advance online publication. https://doi.org/10.1007/s12187-019-09644-4.

Norris, A. E., Aroian, K. J., \& Warren, S. (2012). Interactive performance and focus groups with adolescents: The power of play. Research in Nursing \& Health, 35(6), 671-679. https://doi.org/10.1002/nur.21509.

O'Hare, W. P. (2012). Development of the child indicator movement in the United States. Child Development Perspectives, 6(1), 79-84. https://doi.org/10.1111/j.1750-8606.2011.00214.x.

O'Hare, W. P., \& Gutierrez, F. (2012). The use of domains in constructing a comprehensive composite index of well-being. Child Indicators Research, 5(4), 609-629. doi.org/10.1007/s12187-012-9138-6.

Schwartz, S. H. (1992). Universals in the content and structure of values: Theory and empirical tests in 20 countries. In M. Zanna (Ed.), Advances in experimental social psychology (Vol. 25, pp. 1-65). New York: Academic Press.

Schwartz, S. H. (2006). Les valeurs de base de la personne: Théorie, mesures et applications [Basic human values: Theory, measurement, and applications]. Revue Francaise de Sociologie, 47, 249-288.

Schwartz, S. H. (2011). Studying values: Personal adventure, future directions. Journal of Cross-Cultural Psychology, 42(2), 307-319. https://doi.org/10.1177/0022022110396925.

Schwartz, S., \& Bardi, A. (1997). Influences of adaptation to communist rule on value priorities in Eastern Europe. Political Psychology, 18(2), 385-410. https://doi.org/10.1111/0162-895X.00062.

Schwartz, S. H., Cieciuch, J., Vecchione, M., Davidov, E., Fischer, R., Beierlein, C., et al. (2012). Refining the theory of basic individual values. Journal of Personality and Social Psychology, 103(4), 663-688. https://doi.org/10.1037/a0029393.

Steinberg, L., \& Monahan, K. C. (2007). Age differences in resistance to peer influence. Developmental Psychology, 43(6), 1531-1543. https://doi.org/10.1037/0012-1649.43.6.1531.

Tamis-LeMonda, C. S., Way, N., Hughes, D., Yoshikawa, H., Kalman, R. K., \& Niwa, E. Y. (2008). Parents' goals for children: The dynamic coexistence of individualism and collectivism in cultures and individuals. Social Development, 17(1), 183-209. https://doi.org/10.1111/j.1467-9507.2007.00419.x.

Tedeschi, R. G., \& Calhoun, L. G. (1995). Trauma \& transformation: Growing in the aftermath of suffering. Thousand Oaks: Sage Publications, Inc..

Triandis, H. C. (1995). Individualism \& collectivism. Boulder, Oxford: Westview Press.

Vogl, S. (2005). Gruppendiskussion mit Kindern: Methodische und methodologische Besonderheiten. In Zentralarchiv für Empirische Sozialforschung (Ed.), ZA-Information 57 (pp. 28-60). Köln: Universität zu Köln.

Vujčić, M. T., Brajša-Žganec, A., \& Franc, R. (2019). Children and young peoples' views on well-being: A qualitative study. Child Indicators Research, 12(3), 791-819. https://doi.org/10.1007/s12187-018-9559y.

Wernesjö, U. (2011). Unaccompanied asylum-seeking children: Whose perspective? Childhood, 19(4), 495507. https://doi.org/10.1177/0907568211429625.

White, S. C. (2008) But what is well-being? A framework for analysis in social and development policy and practice, WeD Working Paper 43. http://staff.bath.ac.uk/ecsscw/But_what_is_Wellbeing.pdf. Accessed 15 September 2019.

White, S. C. (2010). Analysing wellbeing: A framework for development practice. Development in Practice, 20(2), 158-172. https://doi.org/10.1080/09614520903564199. 
Publisher's Note Springer Nature remains neutral with regard to jurisdictional claims in published maps and institutional affiliations.

\section{Affiliations}

\section{Silvia Exenberger ${ }^{1} \cdot$ Stefanie Reiber $^{2}$}

1 Department of Medical Psychology, Medical University of Innsbruck, Speckbacherstr. 23/3, 6020 Innsbruck, Austria

2 Department of Psychology, University of Innsbruck, Bruno-Sander-Haus, Innrain 52f, 6020 Innsbruck, Austria 